\title{
Impact and synergies of GIM error estimates on the VTEC interpolation and single-frequency PPP at low latitude region
}

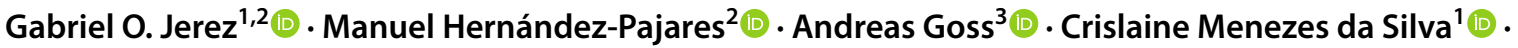 \\ Daniele B. M. Alves ${ }^{1} \mathbb{D}$. João F. G. Monico ${ }^{1} \mathbb{D}$
}

Received: 15 June 2021 / Accepted: 21 December 2021 / Published online: 22 January 2022

(c) The Author(s) 2022

\begin{abstract}
The vertical total electron content (VTEC) is one of the key quantities to describe variations of the ionosphere and can be provided to users to correct the ionospheric disturbances for GNSS (Global Navigation Satellite System) positioning. The VTEC values and the corresponding standard deviations are routinely provided in the so-called Global Ionosphere Maps (GIM), with a typical time resolution of $2 \mathrm{~h}$ (and up to $15 \mathrm{~min}$ ) on regular grids with $2.5^{\circ}$ resolution in latitude and $5^{\circ}$ resolution in longitude. To determine the ionospheric corrections from the GIMs for positioning applications, an interpolation has to be applied to the VTEC grid values, which generally degenerates the final VTEC accuracy. In this context, the typically applied bi-linear interpolation of the VTEC values is calculated by introducing a new weighting scheme by means of the standard deviation maps in the ionospheric domain. In the sequel, the impact of the use of the VTEC uncertainties for the interpolation procedure is applied to the GIMs of different centers and assessed in the ionospheric and in the positioning domain. For the assessment of the GIM in the ionospheric domain, the VTEC values calculated are compared with VTEC directly obtained from the given GIM, i.e., without interpolation. In the positioning domain, the impact of the VTEC uncertainties is analyzed by means of single-frequency precise point positioning (PPP), considering four Brazilian stations in challenging regions. The use of the standard deviation values in positioning provides a significant improvement in periods of high solar flux, especially for stations in the region under more intense ionospheric effect (mean rates of improvements up to $47 \%$ ).
\end{abstract}

Keywords Ionosphere $\cdot$ Global ionospheric maps $\cdot$ GNSS positioning $\cdot$ PPP $\cdot$ Equatorial region

\section{Introduction}

The free electrons in the earth's ionosphere can significantly impact the propagation of radio waves, in particular in L-band affecting GNSS-based applications. In ionosphere studies, the effect of the electrons on the propagation of GNSS signals is mostly based on the very same observations. To be more specific, the number of electrons along the

Gabriel O. Jerez

gabriel.jerez@unesp.br

1 Department of Cartography, São Paulo State University (UNESP), Presidente Prudente, São Paulo 19060-900, Brazil

2 Department of Mathematics, UPC-IonSAT and UPC-IEEC Research Groups, Universitat Politècnica de Catalunya (UPC), 08034 Barcelona, Spain

3 Deutsches Geodätisches Forschungsinstitut der Technischen Universität München, Arcisstraße 21, 80333 Munich, Germany transmitter-receiver line-of-sight in the ionosphere (hereinafter electron density $N_{e}(\varphi, \lambda, h, t)$, function of the latitude $\varphi$, the longitude $\lambda$, the height $h$ and the time $t$ ). In other words, the multi-frequency GNSS measurements provide the information about the so-called Slant Total Electron Content (STEC),

$\operatorname{STEC}\left(\boldsymbol{x}_{R}, \boldsymbol{x}^{S}, t\right)=\int_{T}^{R} N_{e}(\varphi, \lambda, h, t) \mathrm{ds}$

as the integral along the ray path between the positions $\boldsymbol{x}^{S}$ and $\boldsymbol{x}_{R}$ of the transmitting satellite and the receiver, respectively, with the position vector $\boldsymbol{x}=r[\cos \varphi \cos \lambda, \cos \varphi \sin \lambda, \sin \varphi]^{T}$, with $r$ as the radial distance in a geocentric coordinate system. For ionosphere modeling, to relate the STEC and the VTEC (Vertical Total Electron Content), typically the so-called Single-Layer Model (SLM) is applied, where it is assumed that all electrons are concentrated on a spherical layer of infinitesimal 
thickness and with radius $H=R_{e}+h$ at an assumed ionospheric effective height $\mathrm{h}$ above a spherical Earth of radius $R_{e}$. Applying a zenith angle $z$ depending mapping function $M(z)$ to the STEC values from GNSS yields the $\operatorname{VTEC}(\varphi, \lambda, t)$ as the integral along the height (Mannucci et al. 1998; Hernández-Pajares et al. 1999; Dach et al. 2015). Since 1998, several Ionosphere Associated Analysis Centers (IAACs) of International GNSS Service (IGS) have been working on methods to compute and openly provide maps of VTEC, the so-called Global Ionosphere Maps (GIM) (Hernández-Pajares et al. 2009). These GIMs are typically disseminated using the so-called IONosphere EXchange format (IONEX), which comprises snapshot maps of VTEC values given on regular grids with $2.5^{\circ} \times 5^{\circ}$ resolution in latitude and longitude, respectively, and with a temporal sampling of two hours (Schaer et al. 1998). Currently, the IAACs providing GIMs are CODE (Center for Orbit Determination in Europe), ESA/ESOC (European Space Agency/European Space Operations Centre), JPL (Jet Propulsion Laboratory), UPC (Universitat Politècnica de Catalunya), WHU (Wuhan University), CAS (Chinese Academy of Science), NRCan (Natural Resources Canada) and most recently OPTIMAP/ DGFI-TUM (Operational Tool for Ionospheric Mapping And Prediction/Deutsches Geodätisches Forschungsinstitut- Technische Universität München) (Feltens and Schaer 1998; Roma-Dollase et al. 2018).

Besides the $2.5^{\circ} \times 5^{\circ}$ (latitude $x$ longitude) spatial resolution, GIMs are typically provided at a two-hour sampling between two consecutive maps, as previously mentioned. The calculation of the ionospheric corrections for positioning applications by means of GIM requires interpolation of the regular grid to the specific IPP (ionospheric pierce point) of the observation to be corrected. The interpolation accuracy is inversely proportional to the spatial and temporal resolution of the maps. In addition to the estimated VTEC values, their estimated standard deviations, presented as "RMS" (root mean squared) in the IONEX format, are also available at most of the GIMs provided by means of such a format. However, in the original VTEC interpolation equation presented by Schaer et al. (1998), the error estimates (standard deviations) of VTEC grid are not considered. Those values can be used in the interpolation methods for weighting, which can lead to a better calculation of the ionospheric correction. In this way, the VTEC interpolation would not solely rely on the distance from the grid values. As far as the authors could find, no previous studies clearly explore those important indicators of the quality of the VTEC values, concerning its influence in the VTEC interpolation or its impact on the GNSS positioning.

Regarding the assessment of GIMs at the ionospheric domain, it is usually based on comparisons with two complementary sources of reference data: VTEC obtained with altimeters and STEC (slant TEC) variability from independent stations (Hernández-Pajares et al. 2017b; RomaDollase et al. 2018; Ho et al. 1997; Erdogan et al. 2020). Other GIM assessment approaches consider comparisons with different GIMs (Orús et al. 2005; Goss et al. 2019), models such as the International Reference Ionosphere (Meza et al. 2002), measurements gathered from vessels (Luo et al. 2017; Wang et al. 2019), variability of DCBs (Rovira-Garcia et al. 2016) and ionosonde data (Prol et al. 2018; Jerez et al. 2020). Another possible way of assessing ionospheric models can be performed on the positioning domain. Many studies used this approach to verify the quality of different methodologies to compute VTEC maps at global (Orús 2017; Zhang et al. 2019; Rovira-Garcia et al. 2020; Wang et al. 2020a) and regional (Prol et al. 2018; Tomaszewski et al. 2020; Wang et al. 2020a, b) levels. Besides some differences in the strategies used, such as observables, estimation of DCB (differential code bias) and models for estimating the tropospheric delay, in general, the precise point positioning (PPP) is applied.

In this context, we present a two-way strategy to assess the impact of VTEC RMS from GIMs on the calculation of the ionospheric correction. First, we analyze a method of VTEC interpolation also weighted by RMS values provided by GIMs. Then, we investigate the influence of the use of VTEC uncertainties from GIM on the GNSS positioning. The method proposed and assessment strategies used are presented in the next section. In the dataset, we present the products assessed, cases considered and processing strategy. Then, results are presented in the ionospheric domain, considering global and regional approaches, and in the positioning domain, considering one of the most challenging cases, the Brazilian region. The last section presents the summary and conclusions.

\section{Method of interpolation and strategies of assessment}

Given are the maps for $\operatorname{VTEC}\left(\varphi_{j}, \lambda_{k}, t_{i}\right)$ and $R M S\left(\varphi_{j}, \lambda_{k}, t_{i}\right)$ as regular grids of $j=1, \ldots, J$ latitudes $\varphi_{j}=-90^{\circ}+(j-1) \cdot \Delta \varphi$ with sampling $\Delta \varphi=180^{\circ} /(J-1)$ and $k=1, \ldots, K$ longitudes $\lambda_{k}=0^{\circ}+(k-1) \bullet \Delta \lambda$ with $\Delta \lambda=360^{\circ} / K$ in a geocentric coordinate system and at consecutive time moments $t_{i}+\Delta t$ of temporal sampling $\Delta t$. By means of bivariate interpolation, according to Schaer et al. (1998) the values $\operatorname{VTEC}\left(\varphi, \lambda, t_{i}\right)$ at arbitrary spatial locations $P\left(\varphi=\varphi_{j}+p \Delta \varphi, \lambda=\lambda_{k}+q \Delta \lambda\right)$ with $0 \leq p \leq 1$ and $0 \leq q \leq 1$ can be calculated as 


$$
\begin{aligned}
& \operatorname{VTEC}\left(\varphi_{j}+p \Delta \varphi, \lambda_{k}+q \Delta \lambda, t_{i}\right) \\
& =(1-q) \cdot(1-p) \cdot \operatorname{VTEC}\left(\varphi_{j}, \lambda_{k}, t_{i}\right) \\
& \quad+q(1-p) \cdot \operatorname{VTEC}\left(\varphi_{j}, \lambda_{k}+\Delta \lambda, t_{i}\right) \\
& \quad+(1-q) \cdot p \cdot \operatorname{VTEC}\left(\varphi_{j}+\Delta \varphi, \lambda_{k}, t_{i}\right) \\
& \quad+q \cdot p \cdot \operatorname{VTEC}\left(\varphi_{j}+\Delta \varphi, \lambda_{k}+\Delta \lambda, t_{i}\right)
\end{aligned}
$$

using the nearest four VTEC values. A similar interpolation can be performed for the RMS maps that yield $R M S\left(\varphi, \lambda, t_{i}\right)$.

In order to calculate the VTEC for arbitrary time moments $t_{i} \leq t \leq t_{i+1}$ between consecutive rotated VTEC grids assuming VTEC stationarity in local-time, we introduce the rotated longitudes for the previous and next available GIM considering the time of interpolation $\mathrm{t}: \lambda_{i}^{\prime}=\lambda+\left(t-t_{i}\right)$ and $\lambda_{i+1}^{\prime}=\lambda+\left(t-t_{i+1}\right)$, expressed in the common angle units and taking into account that $1 \mathrm{~h}=15^{\circ}$. The VTEC at the rotated longitudes can be calculated by the linear interpolation obtained from Eq. (2), considering $\mathrm{q}=l$ and constant latitude $(p=0)$ :

$$
\begin{aligned}
& \operatorname{VTEC}\left(\varphi_{j}, \lambda_{k}^{\prime}, t_{i}\right)=\operatorname{VTEC}\left(\varphi_{j}, \lambda_{k}+l \Delta \lambda, t_{i}\right)=(1-l) \\
& \operatorname{VTEC}\left(\varphi_{j}, \lambda_{k}, t_{i}\right)+l \cdot \operatorname{VTEC}\left(\varphi_{j}, \lambda_{k}+\Delta \lambda, t_{i}\right)
\end{aligned}
$$

with $0 \leq l \leq 1$. After calculating the four rotated $\operatorname{VTEC}\left(\varphi_{j}, \lambda_{k}^{\prime}, t_{i}\right)$ at times $t_{i}$ and $t_{i+1}$, Eq. (2) is used for spatial interpolation. After the spatial interpolation at times $t_{i}$ and $t_{i+1}$, the interpolation in time was calculated using:

$\operatorname{VTEC}(\varphi, \lambda, t)=\frac{t_{i+1}-t}{t_{i+1}-t_{i}}$

$\operatorname{VTEC}_{i}\left(\varphi, \lambda_{k}^{\prime}, t_{i}\right)+\frac{t-t_{i}}{t_{i+1}-t_{i}} \operatorname{VTEC}_{i+1}\left(\varphi, \lambda_{k}^{\prime}, t_{i+1}\right)$

Interpolation formulas (2), (3) and (4) allow for calculation of VTEC at any arbitrary point in time and space. However, the accuracy of the interpolated values decreases with increasing sampling $\Delta \varphi, \Delta \lambda$ and $\Delta t$, see e.g. Liu et al. (2021), Goss et al. (2019) and Goss et al. (2021). Improvements can be searched by empirically introducing additional factors $f_{1}$ and $f_{2}$ as a weighting of the consecutive VTEC values in (3) taking into account its estimated errors. In this regard, we adapt Eq. (3) as

$$
\begin{aligned}
& \operatorname{VTEC}_{\mathrm{RMS}}\left(\varphi_{j}, \lambda_{k}+l \Delta \lambda, t_{i}\right)=f_{1} \cdot(1-l) . \\
& \operatorname{VTEC}\left(\varphi_{j}, \lambda_{k}, t_{i}\right)+f_{2} \cdot l \cdot \operatorname{VTEC}\left(\varphi_{j}, \lambda_{k}+\Delta \lambda, t_{i}\right)
\end{aligned}
$$

where $\mathrm{VTEC}_{\mathrm{RMS}}$ is the VTEC calculated with RMS weighting factors $\left(f_{1}\right.$ and $\left.f_{2}\right)$ :

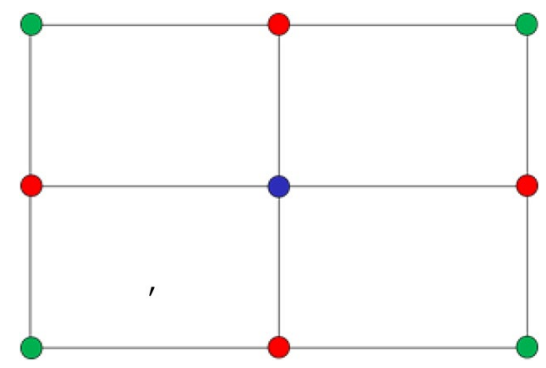

Fig. 1 Geometry of the points used to calculate VTEC values from GIM at a given position (blue) considering: the four closest points with the same geometry of a usual interpolation (green); the four closest points (red); and the eight closest points (green and red)

$$
\begin{aligned}
f_{1} & =\frac{\operatorname{RMS}\left(\varphi_{j}, \lambda_{k}+\Delta \lambda, t_{i}\right)^{2}}{\operatorname{RMS}\left(\varphi_{j}, \lambda_{k}, t_{i}\right)^{2}+\operatorname{RMS}\left(\varphi_{j}, \lambda_{k}+\Delta \lambda, t_{i}\right)^{2}} \text { and } \\
f_{2} & =\frac{\operatorname{RMS}\left(\varphi_{j}, \lambda_{k}, t_{i}\right)^{2}}{\operatorname{RMS}\left(\varphi_{j}, \lambda_{k}, t_{i}\right)^{2}+\operatorname{RMS}\left(\varphi_{j}, \lambda_{k}+\Delta \lambda, t_{i}\right)^{2}}
\end{aligned}
$$

with $\operatorname{RMS}\left(\varphi_{j}, \lambda_{k}, t_{i}\right)$ and $\operatorname{RMS}\left(\varphi_{j}, \lambda_{k}+\Delta \lambda, t_{i}\right)$ provided by the given GIM. This way, the standard deviation of the VTEC values provided at GIMs are also considered in the interpolation strategy as well as the distance from the grid. Then it can be considered a distance-estimated error hybrid GIM interpolation.

The assessment of the influence of VTEC uncertainties is performed at two domains: ionospheric and positioning. The ionospheric domain assessment is based on the calculation of each cell of the GIM considering the neighbor points. Three approaches are considered for calculating the VTEC values, based on: the four closest points with the same geometry of a usual interpolation inside each cell (green); the four closest points (red); and the eight closest points (green and red) as shown in Fig. 1.

The values interpolated $\left(\right.$ VTEC $\left.^{\prime}\right)$, with and without weighting, are then compared with the corresponding original value from the GIM ( VTEC $_{\text {GIM }}$ ). The RMS of those differences $\left(\mathrm{RMS}_{\mathrm{ION}}\right)$ was used to assess the methods of interpolation:

$\mathrm{RMS}_{\mathrm{ION}}=\sqrt{\frac{1}{n} \sum_{i=1}^{n}\left(\mathrm{VTEC}_{\mathrm{GIM}}-\mathrm{VTEC}^{\prime}\right)^{2}}$

where $n$ is the number of values calculated. The assessment is performed at global and regional levels. The regional analysis considers a latitudinal approach (six regions divided by latitudes), as presented in Fig. 2; an approach in four distinct regions (with $20^{\circ} \times 25^{\circ}$ in latitude and longitude each), corresponding to part of United States, Europe, Brazil and Australia, as shown in Fig. 3. 


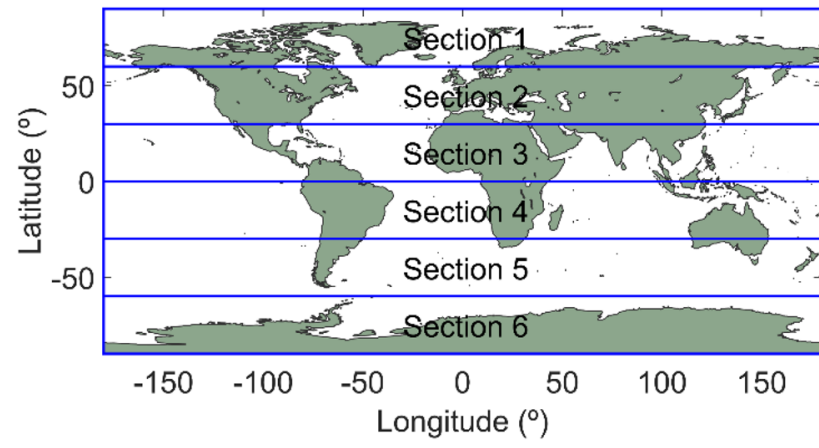

Fig. 2 Analysis considering six sections divided by latitude

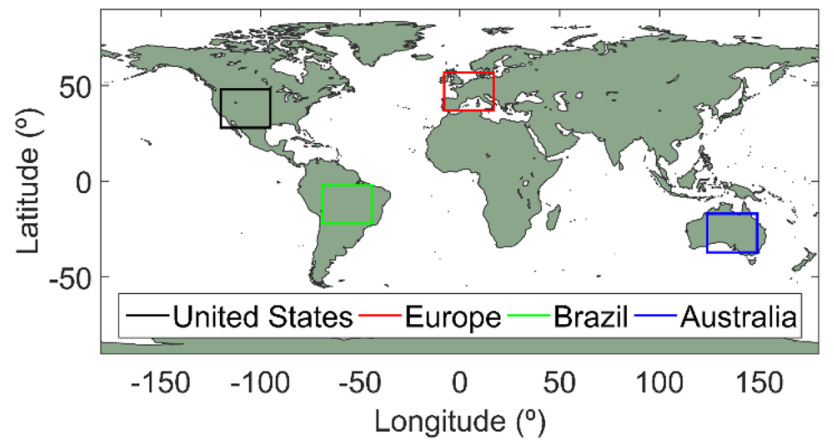

Fig. 3 Analysis considering four regions

The assessment of GIM is also performed at the positioning domain, considering one of the most challenging scenarios, the Brazilian region. In this approach, data from Brazilian GNSS stations are used in single-frequency PPP in kinematic mode. As reference position, we use the mean values of the positions obtained for one week processed in double-frequency PPP in static mode with ion-free combination and the other configuration settings followed the same strategy used for the kinematic processing. For the analysis, the RMS of the positioning error is calculated with:

$\mathrm{RMS}_{\mathrm{POS}}=\sqrt{\frac{1}{n} \sum_{i=1}^{n}\left(\left(X_{\mathrm{Pos}}-X_{\mathrm{Sta}}\right)^{2}+\left(Y_{\mathrm{Pos}}-Y_{\mathrm{Sta}}\right)^{2}+\left(Z_{\mathrm{Pos}}-Z_{\mathrm{Sta}}\right)^{2}\right)}$

where $X_{\mathrm{Pos}}, Y_{\mathrm{Pos}}$ and $Z_{\mathrm{Pos}}$ are the positions obtained with the kinematic processing; $X_{\mathrm{Sta}}, Y_{\mathrm{Sta}}$ and $Z_{\mathrm{Sta}}$ are the mean positions obtained with static processing. The rates of improvement (RoI) of positioning are calculated using:

$\mathrm{RoI}=\frac{\mathrm{RMS}_{\mathrm{GIM} \_\mathrm{RMS} \_ \text {off }}-\mathrm{RMS}_{\mathrm{GIM} \_\mathrm{RMS} \_ \text {on }}}{\mathrm{RMS}_{\mathrm{GIM} \_\mathrm{RMS} \_ \text {off }}}$

where $\mathrm{RMS}_{\mathrm{GIM} \_R M S \_o f f}$ and $\mathrm{RMS}_{\mathrm{GIM} \_R M S \_o n}$ are the results with the positioning using GIM without and with uncertainties, respectively.

\section{Dataset}

Two IGS GIM products are assessed in this work, CODG (final solution of CODE) and UQRG (rapid high-rate solution of UPC, with one map every $15 \mathrm{~min}$ ) available at CDDIS (2020). A third product, called UQ-6, is also analyzed: it is a UQRG version with an offset of 6 TECU subtracted from the RMS to recover the original RMS values instead of the included protection level values (see Zhao et al. 2021). Figure 4 shows the plots of VTEC and respective RMS values from each product used in this study for day 261 of 2011. Four weeks of data are used considering cases with geomagnetic storm, low solar flux and high solar flux (equinox and solstice). Those cases have shown being representatives, as previously presented by Hernandez-Pajares et al. (2017a, b). Table 1 presents the four cases used with the corresponding description, days of year (DOY) and year.

For the positioning approach, we use data of four GNSS stations from the Brazilian Network for Continuous Monitoring (RBMC, acronym in Portuguese) (Fig. 5): MAPA in Macapá-AP (0.05 N, 50.90 W), SAVO in Salvador-BA (11.06 S, 37.57 W), PPTE in Presidente Prudente-SP (21.88 S, $50.59 \mathrm{~W}$ ) and SMAR in Santa Maria-RS (28.28 S, 52.28 W).

The software RTKLib (version 2.4.2) is used to estimate the position of the stations, with single-frequency PPP in kinematic mode, except by the ion-free approach (used as reference positions). The general configuration used is: combined solution with forward and backward filter solutions; $10^{\circ}$ elevation mask; earth tides corrections; Saastamoinen model for the tropospheric delay calculation; precise ephemerides (sp3); GPS constellation; satellite antenna PVC (phase center variation) model; phase wind up corrections; GPS Block IIA satellites in eclipse exclusion; RAIM (receiver autonomous integrity monitoring) FDE (fault detection and exclusion) feature; DCB file; and no strategy for ambiguity solution. Four strategies are used for the ionospheric correction calculation: broadcast, IONEX (by interpolating with and without RMS) and ion-free (only configuration where doublefrequency data is used). However, as the focus of this study is the influence of the VTEC RMS in the positioning, we only present the results with the use of IONEX.

\section{Results in ionospheric domain}

We have assessed the three GIMs, CODE, UQRG and UQ-6, in the ionospheric domain at one global and two regional approaches. All analysis considered the three strategies presented in Sect. 2, concerning the selection of the points from the GIM grid used for the interpolation (Fig. 1): four closest points with the same geometry of the usual interpolation; four closest points; and the eight closest points. Results with 

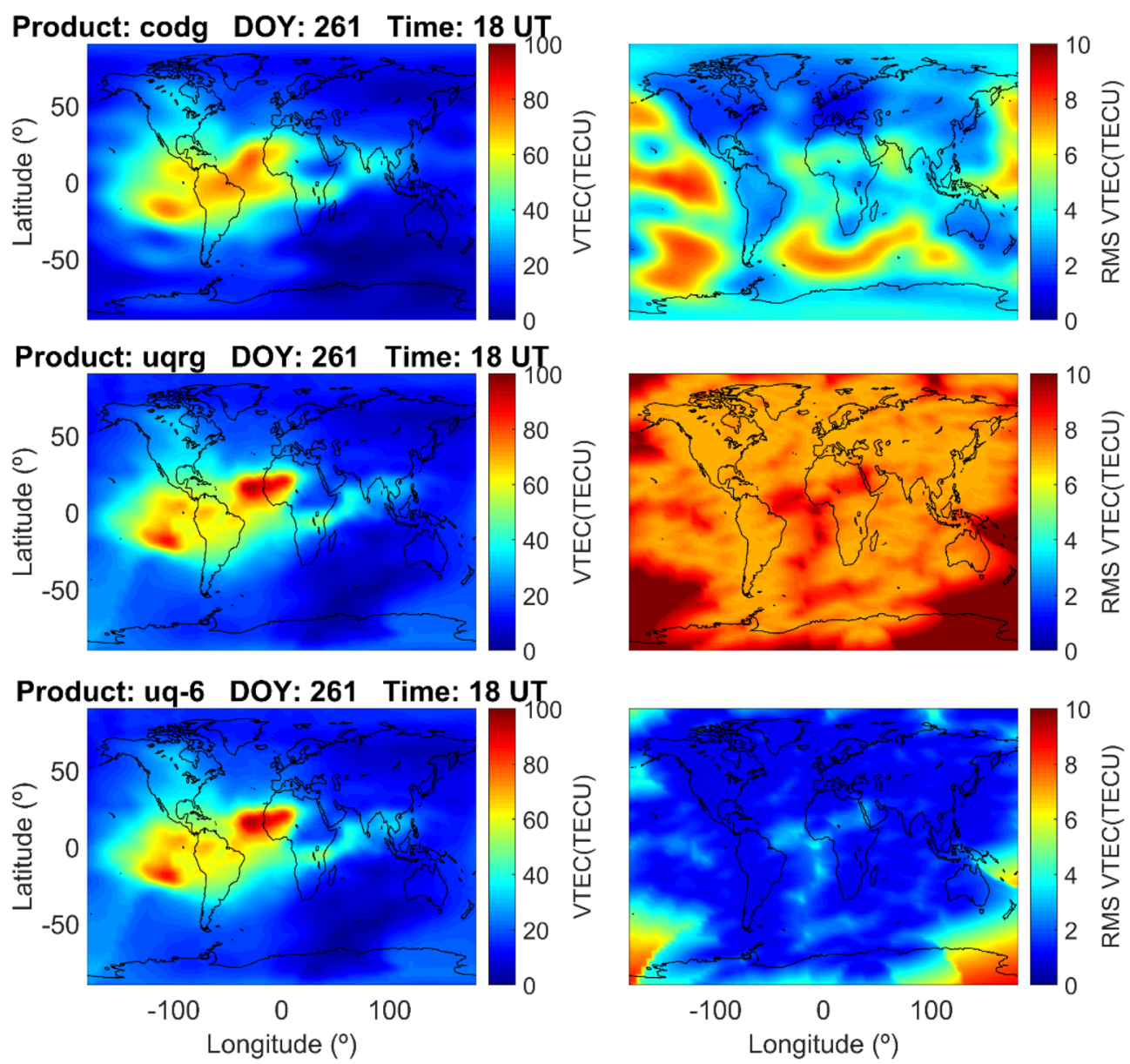

Fig. 4 VTEC and RMS values from: CODG (top row); UQRG (middle row); UQ-6 (bottom row)

Table 1 Description of cases

\begin{tabular}{llll}
\hline Case & Description & DOY & Year \\
\hline 1 & Geomagnetic storm & $346-352$ & 2006 \\
2 & Low solar flux & $234-240$ & 2008 \\
3 & High solar flux (equinox) & $261-267$ & 2011 \\
4 & High solar flux (solstice) & $352-358$ & 2011 \\
\hline
\end{tabular}

and without the RMS weighting presented similar values. In fact, from the first to the third strategy, the results presented even smaller differences. In this way, we present in the sections the results where the largest differences could be noticed, which is the first strategy (four closest points with the same geometry of the usual interpolation).

At the global approach, the main differences between the absolute error for the interpolation strategies were -0.020 TECU (CODG), +0.002 TECU (UQRG) and -0.007 TECU (UQ-6). Table 2 presents the mean absolute errors obtained with the weighting $\left(\mathrm{GIM}_{\mathrm{RMSon}}\right)$ and the simple $\left(\mathrm{GIM}_{\mathrm{RMSoff}}\right)$ interpolations and the differences of both strategies, considering each case for the three products. Concerning the mean absolute error, the values obtained were around 0.29 TECU with CODG, 0.49 TECU with UQRG and 0.52 TECU with UQ-6. Considering the differences, positive values indicate a smaller error by using the weighted interpolation. It can be noticed that, besides the mean values being small, the results with UQRG tended to lead to a better performance with the weighted approach. However, in general, no significant improvement could be noticed by using RMS values to weight the VTEC interpolation at a global level.

The regional analysis was divided into two: (1) by latitude sections; (2) four specific regions-United States, Europe, Brazil and Australia. The differences of RMS between the standard interpolation and the interpolation with the RMS weighting of the four closest point with the same geometry considering the latitudinal sections are presented in Fig. 6 with CODG (a), UQRG (b) and UQ-6 (c). Positive values indicate a smaller error by using the weighted interpolation. It can be noticed that the results from both approaches presented differences close to zero, but there is a certain 


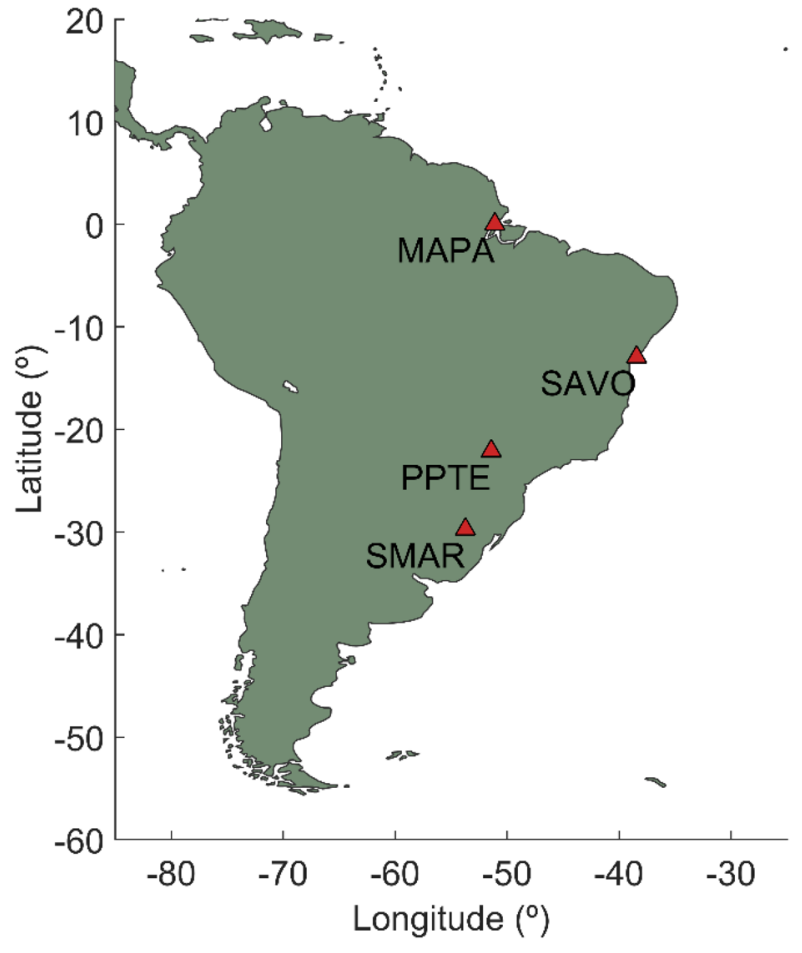

Fig. 5 GNSS stations used in the analysis in the position domain

tendency of better results with the weighted strategy close to the equatorial region (section $-30^{\circ}-0^{\circ}$, presented in blue), mainly considering UQRG and UQ-6.

The differences of RMS between the standard interpolation and the interpolation with the RMS weighting of the four closest point with the same geometry considering the specific regions are presented in Fig. 7 with CODG (a), UQRG (b) and UQ-6 (c). Again, a similar behavior with the one observed in the other approaches was seen. Besides most part of the differences is close to zero, there are some indicators of a best performance of the weighted strategy for the Brazilian region (green), mainly with UQRG and UQ-6.

In general, at the ionospheric domain, no significant improvement was obtained by using the interpolation with weighting based on the uncertainties of VTEC. Case 2 (low ionospheric level) was the one with a smaller difference between the two approaches. Cases 3 and 4 (high ionospheric level) presented the largest differences. It is worth mentioning that no external data was used in this assessment. Only VTEC values from the same GIMs were used as reference. However, besides not presenting significant improvement, some patterns could be noticed, indicating possible regional influence, such as a tendency of slightly better results at the latitude section $0^{\circ}-30^{\circ}$ and at the Brazilian region, mainly with UQRG and UQ-6. We have performed the experiment presented at the next section in the positioning domain to investigate this regional influence, considering the Brazilian region.

\section{Results in positioning domain}

Results from positioning using CODG with (red) and without (blue) uncertainties are presented in Fig. 8, with the mean 3D error versus local time for each week (selected cases in Table 1) considering stations MAPA (a), SAVO (b), PPTE (c) and SMAR (d). It can be noticed that, in general, the smaller errors are observed in the second case (low solar flux). The largest errors occurred at cases 3 and 4 (high solar flux). Concerning the stations, SMAR (located in the region with less ionospheric impact) presents the smaller errors and most regular behavior compared to the other stations. The general positive influence of the use of the uncertainties of VTEC is clear in most part of the time and most significant at the cases with high ionospheric flux. In those cases, it is possible to notice an increase in the error after $20 \mathrm{~h}$ UT up to $4 \mathrm{~h} \mathrm{UT}$, especially for stations SAVO and PPTE.

Figure 9 presents VTEC values at the position of the stations for the first day of each case, calculated using CODG with and without uncertainties. Larger values of VTEC at cases 3 and 4 are clear for all the stations. Concerning the differences between the stations, SMAR presented smaller values most of the time. VTEC values calculated confirm its influence in error obtained in the GNSS positioning.

Figure 10 presents the RMS of the 3D error of positioning using CODG, with (red) and without (blue) uncertainties, for

Table 2 Mean absolute errors obtained with the weighting $\left(\mathrm{GIM}_{\mathrm{RMSon}}\right)$ and simple $\left(\mathrm{GIM}_{\mathrm{RMSoff}}\right)$ interpolations and differences between the two strategies (TECU) for the four selected cases described in Table 1

\begin{tabular}{|c|c|c|c|c|c|c|c|c|c|}
\hline \multirow[t]{2}{*}{ Case } & \multicolumn{3}{|l|}{ CODG } & \multicolumn{3}{|l|}{ UQRG } & \multicolumn{3}{|l|}{ UQ-6 } \\
\hline & $\mathrm{GIM}_{\text {RMSoff }}$ & $\mathrm{GIM}_{\mathrm{RMSon}}$ & Difference & GIM $_{\text {RMSoff }}$ & $\mathrm{GIM}_{\mathrm{RMSon}}$ & Difference & GIM $_{\text {RMSoff }}$ & GIM $_{\text {RMSon }}$ & Difference \\
\hline 1 & 0.1987 & 0.2096 & -0.0109 & 0.4183 & 0.4167 & 0.0016 & 0.3997 & 0.4023 & -0.0026 \\
\hline 2 & 0.1202 & 0.1292 & -0.0089 & 0.2234 & 0.2230 & 0.0003 & 0.2543 & 0.2559 & -0.0015 \\
\hline 3 & 0.4256 & 0.4582 & -0.0326 & 0.6947 & 0.6919 & 0.0028 & 0.7385 & 0.7478 & -0.0094 \\
\hline 4 & 0.3718 & 0.3984 & -0.0266 & 0.6440 & 0.6407 & 0.0033 & 0.6781 & 0.6908 & -0.0127 \\
\hline
\end{tabular}




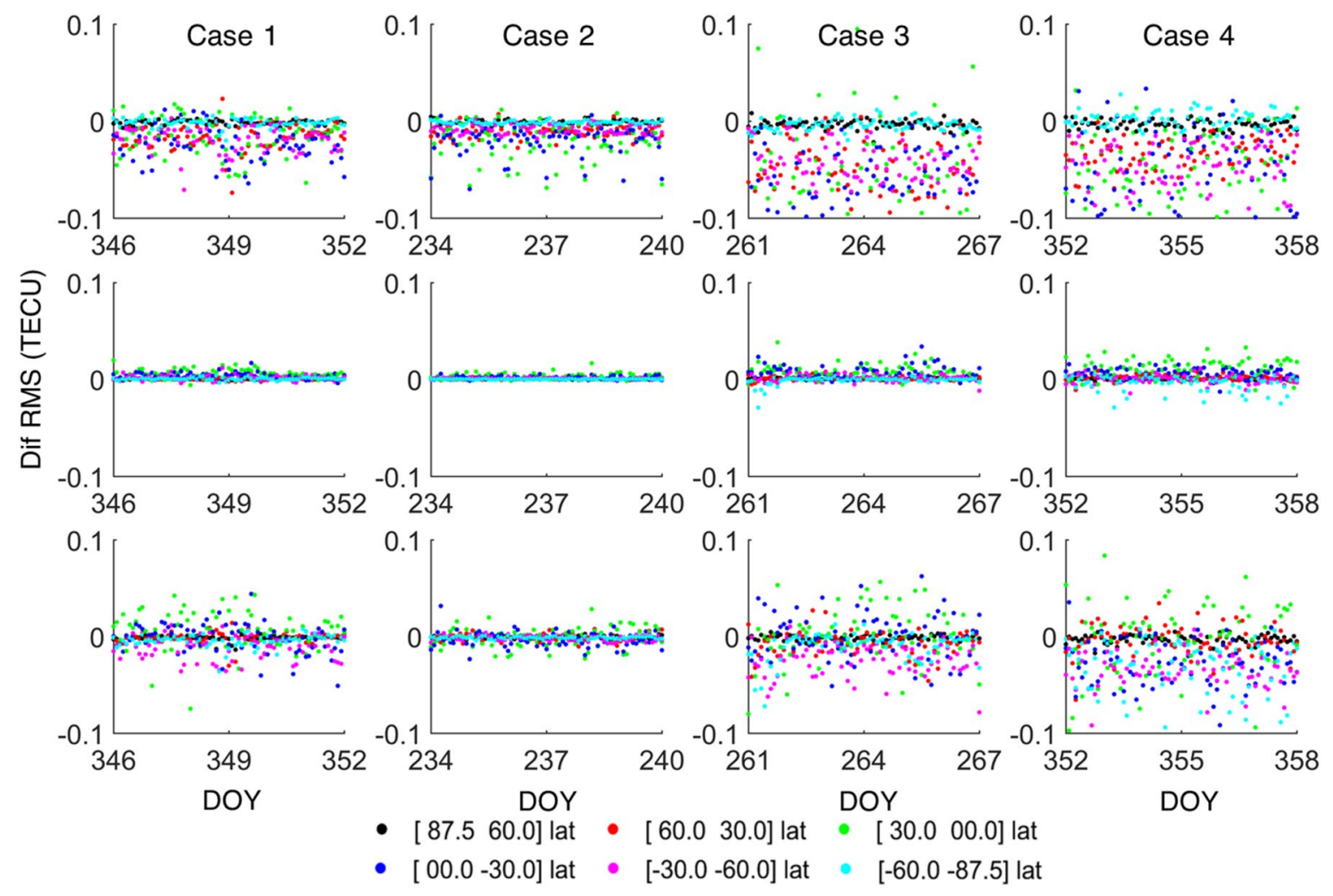

Fig. 6 Differences of the RMS of the VTEC values by section using CODG (top row), UQRG (middle row) and UQ-6 (bottom row)

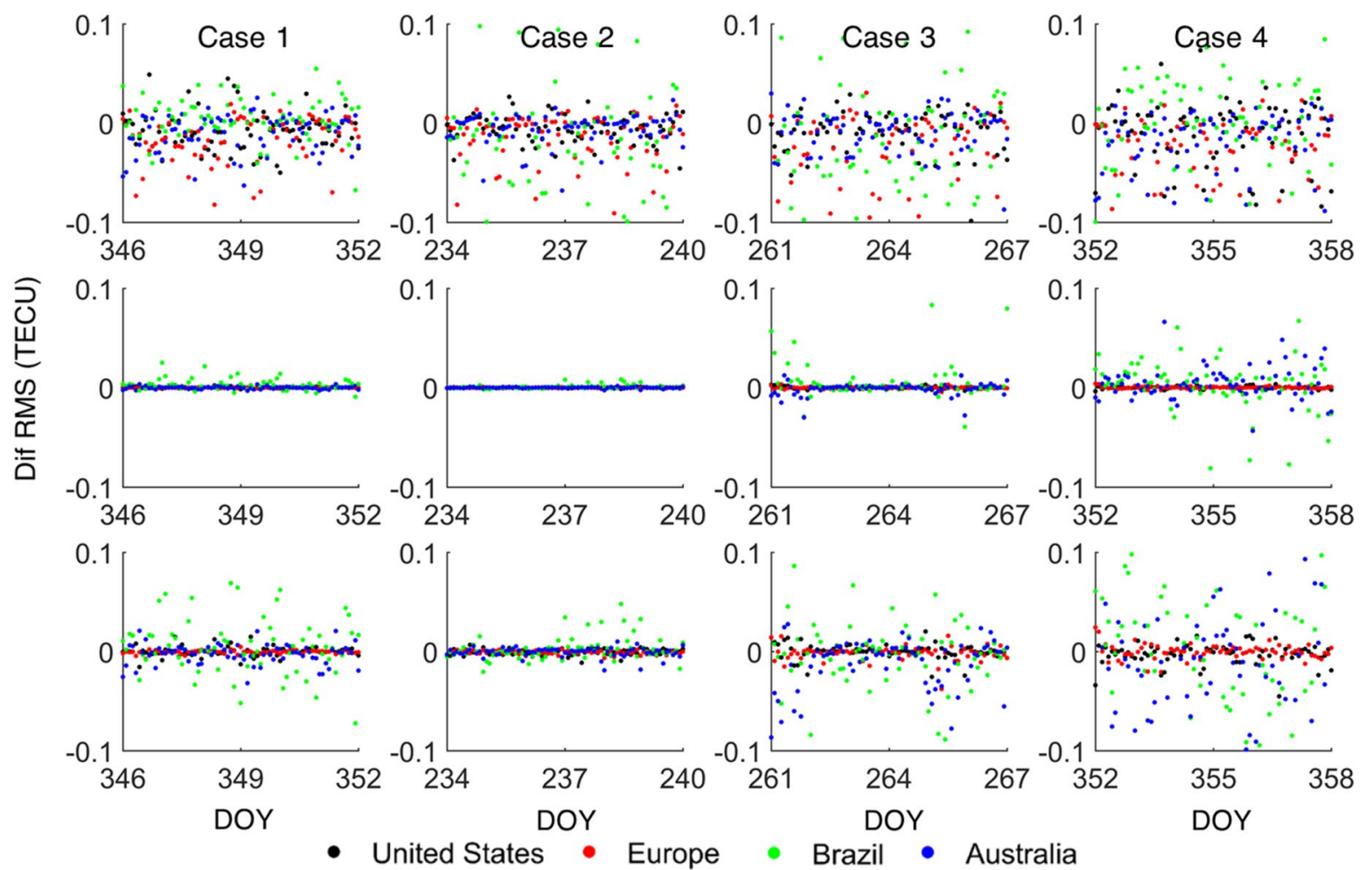

Fig. 7 Differences of the RMS of the VTEC values by region using CODG (top row), UQRG (middle row) and UQ-6 (bottom row) 
Fig. 8 Mean 3D positioning error using CODG GIM, stations: MAPA (top left); SAVO (top right); PPTE (bottom left); and SMAR (bottom right)

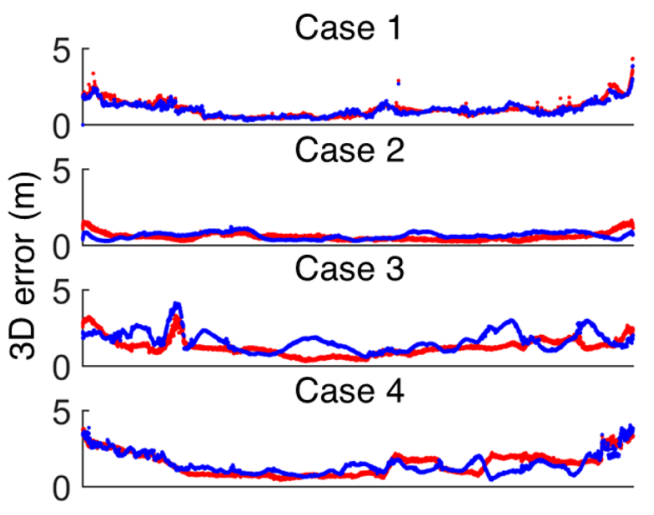

Case 1

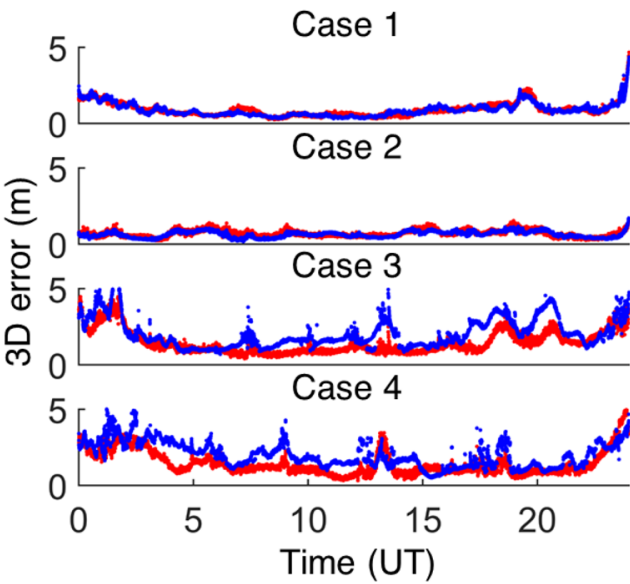

-IONEX+RMSon •IONEX+RMSoff

Fig. 9 VTEC calculated with CODG for the first day of each case over the stations MAPA, SAVO, PPTE and SMAR
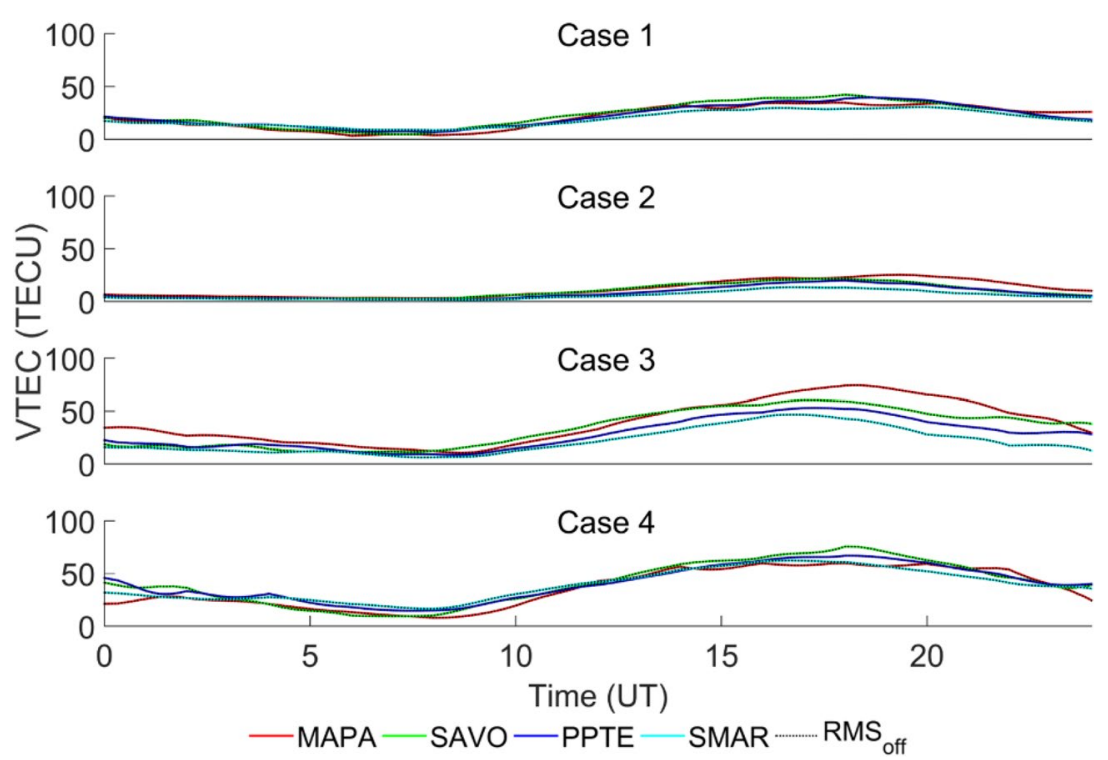

each day of each week for stations MAPA (a), SAVO (b), PPTE (c) and SMAR (d). The results confirm the behavior noticed previously with mean values (Fig. 8), with higher improvement with the use of the RMS weighting when cases 3 and 4 are considered, especially with stations SAVO and PPTE.
Results from positioning using UQRG and UQ-6 presented the same behavior observed with CODG. Similar behavior related to the time of the day (higher values from $20 \mathrm{~h}$ up to $4 \mathrm{~h} \mathrm{UT}$ ), cases with the higher influence of the use of weighting (high solar flux) and the stations with most significant improvement (SAVO and PPTE). Regarding the 
Fig. 10 RMS of 3D error using CODG, stations: MAPA, SAVO, PPTE and SMAR

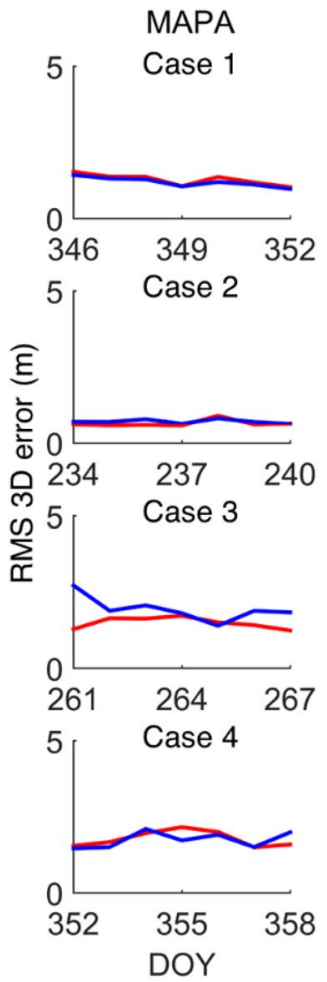

differences between UQRG and UQ-6, it can be seen in Fig. 11 that UQ-6 presents a most consistent behavior: an improvement under the hybrid weighting approach within high solar flux cases ( 3 and 4), and no worsening in the low solar flux case 2 , similarly as in the geomagnetic activity case 1 .

In general, the $3 \mathrm{D}$ errors from positioning obtained with CODG were slightly larger considering the results without weighting, $1.22 \mathrm{~m}$, while UQRG and UQ-6 led to a mean error of $1.17 \mathrm{~m}$. Regarding the approach with weighting, CODG presented a slightly better performance than the two versions of UQRG. CODG presented a mean error of $0.87 \mathrm{~m}$, UQRG $0.94 \mathrm{~m}$ and UQ-6 $0.97 \mathrm{~m}$.

Table 3 presents the rates of improvement by adding the uncertainties of VTEC in the positioning compared to the approach with GIM without RMS. The smallest rates of improvement occurred in the first case, geomagnetic storm, except for PPTE, which presented a mean decrease of $12 \%$ in the second case, low solar flux. SAVO and PPTE present the larger rates of improvement in cases 3 and 4, high solar flux. While MAPA and SMAR had larger improvement rates in cases 2 and 3, low and high solar flux.

The mean rates of improvement by station for each product are presented at Table 4. CODG presented the highest mean rates of improvement for the four stations. UQ-6 is the only GIM not showing any worsening, and it provided better rates of improvement for three stations than UQRG; the exception was SAVO. The mean rates of improvement
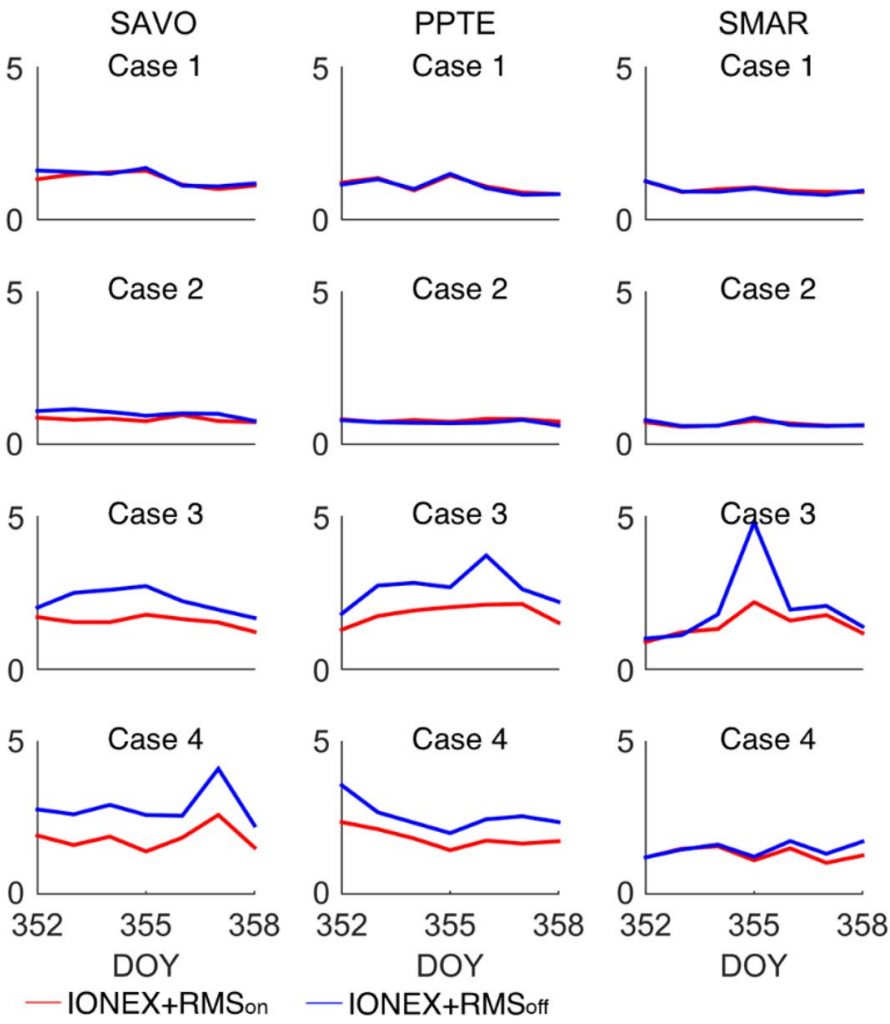

by products were $23 \%, 14 \%$ and $15 \%$, considering CODG, UQRG and UQ-6, respectively.

\section{Summary and conclusions}

We have presented two ways of assessing the influence of VTEC uncertainties in the calculation of VTEC from GIM in the ionospheric and positioning domain in terms of a new associated hybrid weighting approach. The corresponding performance analysis in the ionospheric domain considered a global and two regional approaches. The analysis in the positioning domain was done with four stations in one of the most challenging cases, the Brazilian region. All analyses considered four cases: one week with a geomagnetic storm, one week with low solar flux and two weeks with high solar flux (equinox and solstice). Three ionospheric products were used: CODG, UQRG and UQ-6.

Results from the ionospheric domain considered three approaches regarding the geometry and number of points of the grid used for the interpolation. No significant improvements could be observed in the approaches at global or regional levels. However, some results from the regional approach indicated some pattern of improvement in the use of VTEC uncertainties for the equatorial region (latitude section approach) and the Brazilian region (four regions approach) with UQRG and UQ-6. 
Fig. 11 Mean 3D error using: UQRG for stations PPTE (top left) and SMAR (top right); UQ-6 for stations PPTE (bottom left) and SMAR (bottom right)
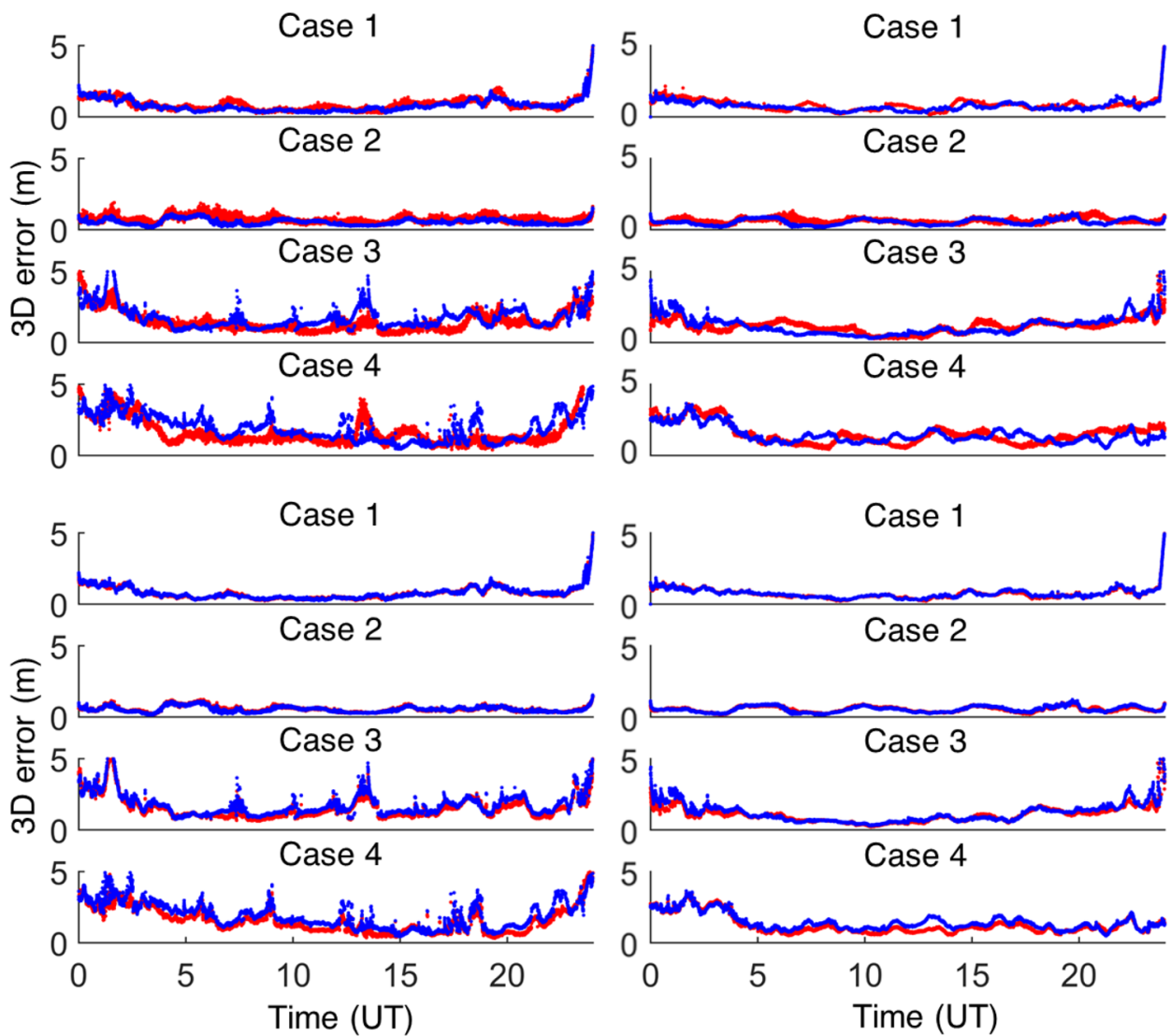

Case 2

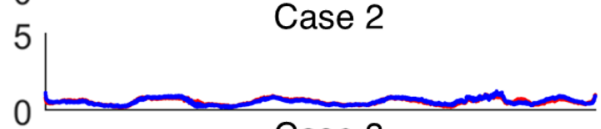

Case 3

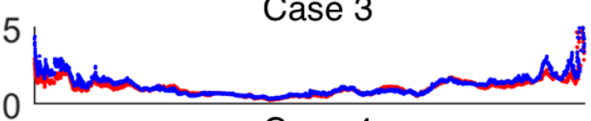

Case 4

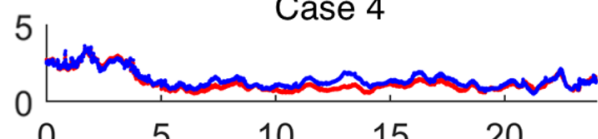

Time (UT)

- IONEX+RMSon $\bullet$ IONEX+RMS off

Table 3 Mean rates of improvement by using RMS weighting by station and case

\begin{tabular}{lllll}
\hline Station & Case & CODG $(\%)$ & UQRG $(\%)$ & UQ-6 (\%) \\
\hline MAPA & 1 & -1 & -6 & 5 \\
& 2 & 32 & 27 & 20 \\
& 3 & 34 & 27 & 17 \\
& 4 & 8 & 3 & 17 \\
SAVO & 1 & 9 & 7 & 10 \\
& 2 & 41 & 25 & 15 \\
& 3 & 38 & 32 & 26 \\
& 4 & 47 & 40 & 27 \\
PPTE & 1 & 4 & -4 & 5 \\
& 2 & 0 & -38 & 3 \\
& 3 & 34 & 28 & 14 \\
& 4 & 37 & 26 & 21 \\
SMAR & 1 & 6 & 0 & 10 \\
& 2 & 23 & 20 & 14 \\
& 3 & 22 & 24 & 18 \\
& 4 & 27 & 6 & 16 \\
\hline
\end{tabular}

Results in the positioning domain showed a clear influence of the total electron content uncertainties on the positioning error. The influence of VTEC in terms of the uncertainties weighting approach led to significant improvements
Table 4 Mean rates of improvement by using RMS weighting by station

\begin{tabular}{llll}
\hline Station & CODG $(\%)$ & UQRG $(\%)$ & UQ-6 (\%) \\
\hline MAPA & 18 & 13 & 15 \\
SAVO & 34 & 26 & 20 \\
PPTE & 19 & 3 & 11 \\
SMAR & 19 & 13 & 14 \\
\hline
\end{tabular}

compared to the performance with GIMs without taking into account their uncertainties. Most significant rates of improvement were observed in cases with high solar flux, especially for stations SAVO and PPTE (located close to geomagnetic latitude $-15^{\circ}$ ). The order of magnitude of errors is in accordance with similar approaches, as presented in Orús (2017) and Prol et al. (2018).

Concerning the general performance of the ionospheric products used, the mean 3D error with CODG presented mean errors at the positioning about $5 \mathrm{~cm}$ larger than UQRG, considering the strategy without RMS. With the use of VTEC RMS, CODG obtained mean errors about $7 \mathrm{~cm}$ smaller than UQRG and $10 \mathrm{~cm}$ smaller than UQ-6. The mean rates of improvement considering all cases and stations for CODG, UQRG and UQ-6 were $23 \%, 14 \%$ and $15 \%$, respectively. 
Consequently, we recommend the usage of the VTEC uncertainties from Ionospheric maps in IONEX format for positioning applications, which can provide an additional improvement in the single-frequency PPP, in particular when low latitude regions and periods of high solar flux are considered.

Acknowledgements We acknowledge the IGS IAACs, in particular, CODE, for providing the ionospheric data, IBGE for providing the GNSS data and the National Institute of Science and Technology for GNSS in Support of Air Navigation (INCT GNSS-NavAer), funded by CNPq (465648/2014-2), FAPESP (2017/50115-0) and CAPES (88887.137186/2017-00). This study was financed in part by the Coordenação de Aperfeiçoamento de Pessoal de Nível Superior - Brasil (CAPES) - Finance Code 001 and Fundação de Amparo à Pesquisa do Estado de São Paulo (FAPESP: 2021/05285-0) with the support as well of the UPC.

Data availability The datasets generated and/or analyzed during the current study are available from the corresponding author on reasonable request.

Open Access This article is licensed under a Creative Commons Attribution 4.0 International License, which permits use, sharing, adaptation, distribution and reproduction in any medium or format, as long as you give appropriate credit to the original author(s) and the source, provide a link to the Creative Commons licence, and indicate if changes were made. The images or other third party material in this article are included in the article's Creative Commons licence, unless indicated otherwise in a credit line to the material. If material is not included in the article's Creative Commons licence and your intended use is not permitted by statutory regulation or exceeds the permitted use, you will need to obtain permission directly from the copyright holder. To view a copy of this licence, visit http://creativecommons.org/licenses/by/4.0/.

\section{References}

CDDIS (2020) GNSS atmospheric products. URL cddis.nasa.gov/ Data and Derived Products/GNSS/atmospheric products.html. Accessed November 2020

Dach R, Lutz S, Walser P, Fridez P (2015) Bernese GNSS software version 5.2. University of Bern, Bern Open Publishing

Erdogan E, Schmidt M, Goss A, Göorres B, Seitz F (2020) Adaptive modeling of the global ionosphere vertical total electron content. Remote Sens 12(11):1822. https://doi.org/10.3390/rs12111822

Feltens J, Schaer S (1998) IGS products for the ionosphere. Tech. rep., European space operation centre and astronomical institute of the university of Berne

Goss A, Schmidt M, Erdogan E, Görres B, Seitz F (2019) High-resolution vertical total electron content maps based on multi-scale b-spline representations. Ann Geophys Copernic GmbH 37:699_ 717. https://doi.org/10.5194/angeo-37-699-2019

Goss A, Hernández-Pajares M, Schmidt M, Roma-Dollase D, Erdogan E, Seitz F (2021) High resolution ionosphere corrections for single-frequency positioning. Remote Sens 13(1):12. https://doi.org/ 10.3390/rs13010012

Hernández-Pajares M, Juan J, Sanz J (1999) New approaches in global ionospheric determination using ground GPS data. J Atmos Sol Terr Phys 61(16):1237-1247. https://doi.org/10.1016/S13646826(99)00054-1

Hernández-Pajares M, Juan J, Sanz J, Orús R, García-Rigo A, Feltens J, Komjathy A, Schaer S, Krankowski A (2009) The
IGS vTEC maps: a reliable source of ionospheric information since 1998. J Geod 83(3-4):263-275. https://doi.org/10.1007/ s00190-008-0266-1

Hernández-Pajares M, Garcia-Fernández M, Rius A, Notarpietro R, von Engeln A, Olivares-Pulido G, Aragón-Àngel A, García-Rigo A (2017a) Electron density extrapolation above $F_{2}$ peak by the linear vary-chap model supporting new global navigation satellite systems-leo occultation missions. J Geophys Res: Space Phys 122(8):9003-9014. https://doi.org/10.1002/2017JA023876

Hernández-Pajares M, Roma-Dollase D, Krankowski A, GarcíaRigo A, Orús-Pérez R (2017b) Methodology and consistency of slant and vertical assessments for ionospheric electron content models. J Geod 91(12):1405-1414. https://doi.org/10.1007/ s00190-020-01346-y

Ho C, Wilson B, Mannucci A, Lindqwister U, Yuan D (1997) A comparative study of ionospheric total electron content measurements using global ionospheric maps of GPS, TOPEX radar, and the bent model. Radio Sci 32(4):1499-1512. https://doi.org/10.1029/ 97RS00580

Jerez GO, Hernández-Pajares M, Prol FS, Alves D, Monico JF (2020) Assessment of global ionospheric maps performance by means of ionosonde data. Remote Sens 12(20):3452. https://doi.org/10. 3390/rs 12203452

Liu Q, Hernández-Pajares M, Lyu H, Goss A (2021) Influence of temporal resolution on the performance of global ionospheric maps. J Geod 95(3):1-16. https://doi.org/10.1007/s00190-021-01483-y

Luo X, Xu H, Li Z, Zhang T, Gao J, Shen Z, Yang C, Wu Z (2017) Accuracy assessment of the global ionospheric model over the Southern Ocean based on dynamic observation. J Atmos Sol Terr Phys 154:127-131. https://doi.org/10.1016/j.jastp.2016.12.017

Mannucci A, Wilson B, Yuan D, Ho C, Lindqwister U, Runge T (1998) A global mapping technique for GPS-derived ionospheric total electron content measurements. Radio Sci 33(3):565-582. https:// doi.org/10.1029/97RS02707

Meza A, Brunini C, Bosch W, VanZele M (2002) Comparing vertical total electron content from GPS, bent and IRI models with TOPEX-Poseidon. Adv Space Res 30(2):401-406. https://doi.org/ 10.1016/S0273-1177(02)00314-9

Orús R (2017) Ionospheric error contribution to GNSS single-frequency navigation at the 2014 solar maximum. J Geod 91(4):397407. https://doi.org/10.1007/s00190-016-0971-0

Orús R, Hernández-Pajares M, Juan J, Sanz J (2005) Improvement of global ionospheric vTEC maps by using kriging interpolation technique. J Atmos Sol Terr Phys 67(16):1598-1609. https://doi. org/10.1016/j.jastp.2005.07.017

Prol FS, Camargo PO, Hernández-Pajares M, Muella MTAH (2018) A new method for ionospheric tomography and its assessment by ionosonde electron density, GPS TEC, and single-frequency PPP. IEEE Trans Geosci Remote Sens 57(5):2571-2582. https://doi. org/10.1109/TGRS.2018.2874974

Roma-Dollase D, Hernández-Pajares M, Krankowski A, Kotulak K, Ghoddousi-Fard R, Yuan Y, Li Z, Zhang H, Shi C, Wang C et al (2018) Consistency of seven different GNSS global ionospheric mapping techniques during one solar cycle. J Geod 92(6):691706. https://doi.org/10.1007/s00190-017-1088-9

Rovira-Garcia A, Juan J, Sanz J, González-Casado G, Ibáñez D (2016) Accuracy of ionospheric models used in GNSS and SBAS: methodology and analysis. J Geod 90(3):229-240. https://doi.org/10. 1007/s00190-015-0868-3

Rovira-Garcia A, Ibáñez-Segura D, Orús-Perez R, Juan JM, Sanz J, Gonzalez-Casado G (2020) Assessing the quality of ionospheric models through GNSS positioning error: methodology and results. GPS Solut 24(1):1-12. https://doi.org/10.1007/ s10291-019-0918-z 
Schaer S, Gurtner W, Feltens J (1998) The IONosphere Map EXchange format version 1. Tech. rep., Astronomical Institue of the University of Berne

Tomaszewski D, Wielgosz P, Rapinski J, Krypiak-Gregorczyk A, Kazmierczak R, Hernández-Pajares M, Yang H, Orús-Pérez R (2020) Assessment of centre national d'etudes spatiales real-time ionosphere maps in instantaneous precise real-time kinematic positioning over medium and long baselines. Sensors 20(8):2293. https://doi.org/10.3390/s20082293

Wang D, Luo X, Wang J, Gao J, Zhang T, Wu Z, Yang C, Wu Z (2019) Global ionospheric model accuracy analysis using shipborne kinematic GPS data in the arctic circle. Remote Sens 11(17):2062. https://doi.org/10.3390/rs11172062

Wang C, Fan L, Wang Z, Shi C (2020a) Assessment of global ionospheric maps over continental areas using precise point positioning technique. J Spat Sci 65(1):25-39. https://doi.org/10.1080/ 14498596.2019.1654943

Wang H, Sui Y, Wang D, Fu H, Feng S (2020b) Undifference PPP method and performance assessment based on regional ionospheric model. In: Sun J, Yang C, Xie J (eds) China Satellite Navigation Conference (CSNC) 2020 Proceedings: Volume II, Springer Singapore, Singapore, pp. 684-695

Zhang L, Yao Y, Peng W, Shan L, He Y, Kong J (2019) Real-time global ionospheric map and its application in single-frequency positioning. Sensors 19(5):1138. https://doi.org/10.3390/s1905 1138

Zhao J, Hernandez-Pajares M, Li Z, Wang N, Yuan H (2021) Integrity investigation of global ionospheric TEC maps for high-precision positioning. J Geod 95(3):1-15. https://doi.org/10.1007/ s00190-021-01487-8

Publisher's Note Springer Nature remains neutral with regard to jurisdictional claims in published maps and institutional affiliations.

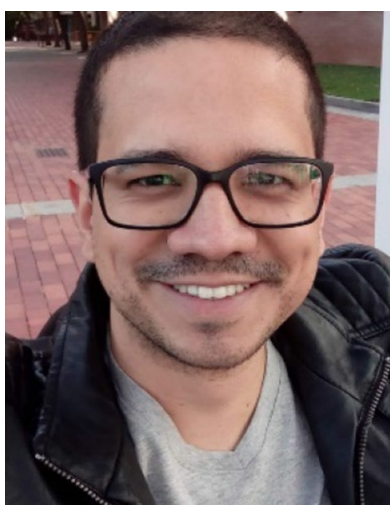

Gabriel Oliveira Jerez is a postdoctoral researcher at São Paulo State University, Presidente Prudente, Brazil. He received a B.S. degree in Cartographic Engineering in 2014 and a M.Sc. and a Ph.D. degree in Cartographic Sciences from São Paulo State University, Brazil, in 2017 and 2021. His research interests include GNSS positioning and radio occultation.

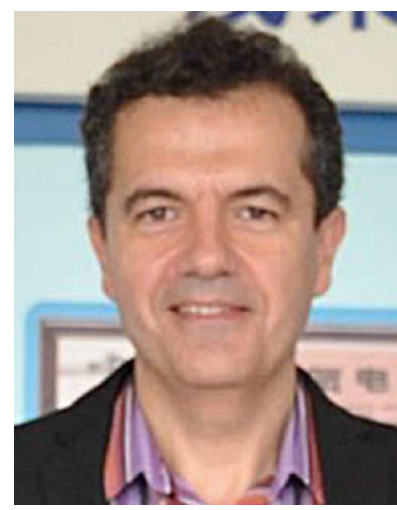

Manuel Hernández-Pajares is a Full Professor at Universitat Politècnica de Catalunya (UPC), Barcelona, Spain. Since 1994 he has focused on new algorithms for precise ionospheric sounding and GNSS navigation. He has been the chair of the International GNSS Service (IGS) Ionosphere WG (2002-2007). He created the new research group UPC-IonSAT in November 2013 and is a member of the IEECCTE research group.

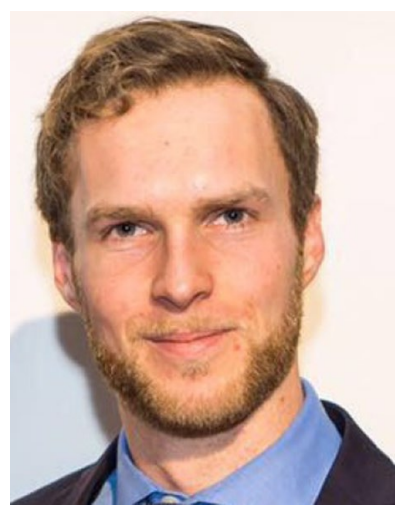

Andreas Goss received his Master's degree in Geodesy and Geoinformation in 2016, and is a research associate and $\mathrm{Ph} . \mathrm{D}$. student at the Deutsches Geodätisches Forschungsinstitut at the Technical University of Munich (DGFI-TUM). His current research activities focus on ionospheric monitoring and high-resolution modeling using observations from various space geodetic techniques.

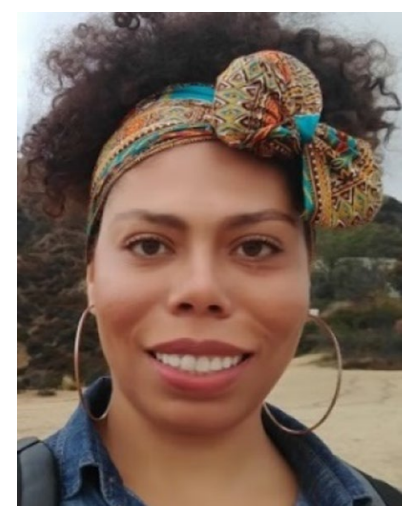

Crislaine Menezes da Silva is currently a postdoctoral researcher at São Paulo State University (UNESP). She received her B.Sc. degree in Mathematics (2012), M.Sc. degree in Applied and Computational Mathematics (2015), and her Ph.D. degree in Cartographic Science (2021) from UNESP. Her research focuses on multi-GNSS and multi-frequency ambiguity resolution and precise positioning applications. 


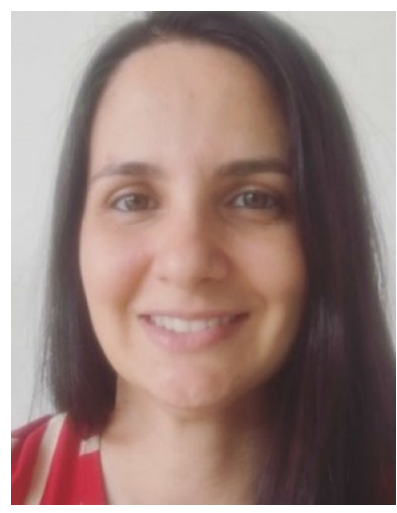

Daniele Barroca Marra Alves is an Assistant Professor at UNESP and Researcher from National Council for Scientific and Technological Development (CNPq). She received her BSc degree in Mathematics in 2001, MSc in 2004, Ph.D. in 2008, and postdoctorate in 2011, all of them in Cartographic Science, from São Paulo State University. Her research interests are atmospheric modeling and GNSS Positioning.

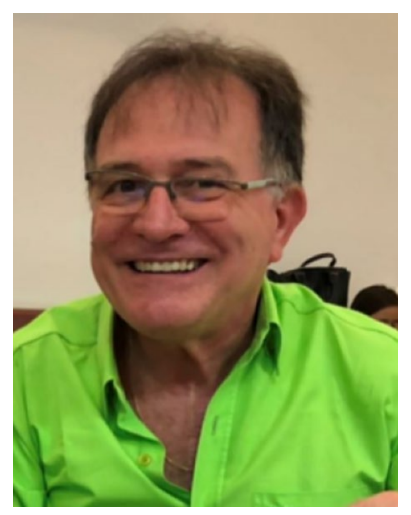

João Francisco Galera Monico is a senior researcher at UNESP. $\mathrm{He}$ has more than 110 peerreviewed publications, published 2 books and 29 chapters, and supervised 5 postdoctoral researchers, 13 Ph.D., and 32 MSc dissertations. His research interest includes GNSS for positioning, navigation, and atmospheric monitoring. 